\title{
High-Pressure Oxygen Insufflation of the Sorbent in Complex Treatment of Clean Soft Tissue Wounds
}

\author{
Dmitry V. Arhipovi ${ }^{1}$ Alexandr A. Andreev, $\mathrm{PhD}, \mathrm{ScD}^{1}$; Alexandr A. Glukhov, $\mathrm{PhD}, \mathrm{ScD}^{1}$; \\ Dmitry A. Atiakshin, $\mathrm{PhD}^{2}$; Anton P. Ostroushko, $\mathrm{PhD}^{1^{*}}$; Sergey N. Boyev, $\mathrm{PhD}^{1}$; \\ Anastasiya Yu. Laptiyova ${ }^{1}$ \\ ${ }^{I} N . N$. Burdenko Voronezh State Medical University \\ ${ }^{2}$ Research Institute of Experimental Biology and Medicine, N. N. Burdenko Voronezh State Medical University \\ Voronezh, the Russian Federation
}

\begin{abstract}
Background: The aim of our research was to study the effectiveness of the potentiation of reparative processes in soft tissues using high-pressure oxygen insufflations of the sorbent (S-HPOI) in the experiment.

Methods and Results: The study included 150 Wistar rats that were divided into 5 groups: four control groups and one experimental group. Each group included 30 animals. The identical soft tissue wounds were simulated in animals of all groups. No additional interventions were carried out in the animals of the control group (CG) 1; high-pressure oxygen and air insufflation of wounds were applied in animals of CG2 and CG3, respectively; sorbent applications were performed for wound treatment in animals of CG4. The technique of S-HPOI was applied in animals of the experimental group (EG). The results of the experiment were assessed immediately after the simulation procedure, and on Days 1, 3, 5, 7, and 14 after wound simulation.

The use of the sorbent applications and S-HPOI contributed to a significant acceleration of reparative processes by 1.11.3 and 1.2-1.5 times, respectively, compared with the results obtained in animals of CG1.The use of high-pressure oxygen has practically no benefits in wound treatment compared to similar intervention using air jet.

Conclusion: On the whole, S-HPOI resulted in the maximum reduction in the area of soft tissue wounds: by $74.0 \%$ in 3 days, by $99.5 \%$ in 10 days compared to the initial findings. (International Journal of Biomedicine. 2020;10(3):247-250.)
\end{abstract}

Key Words: soft tissue wounds $\bullet$ high-pressure oxygen insufflations $\bullet$ sorbent

\section{Abbreviations}

OD, optical density; HPOI, high-pressure oxygen insufflations; S-HPOI, HPOI of the sorbent.

\section{Introduction}

Currently, there is no decrease in the number of patients with soft tissue wounds; this might result from the fact that there is an increase in the number of patients with injuries, neoplasms, ulcers, and comorbid pathology. ${ }^{(1-6)}$ About $1.5 \%$ of

*Corresponding author: Anton P. Ostroushko, PhD. Department of general surgery, N.N. Burdenko Voronezh State Medical University. Voronezh, the Russian Federation. E-mail: antonostroushko@yandex.ru the population and up to $10 \%$ of patients in surgical hospitals suffer from long-term treated wounds, and their treatment is often not only very complicated, but also dramatic. ${ }^{(1)}$ Novel materials, techniques and devices are constantly being introduced into surgical practice to advance clinical outcomes of this group of patients, but their effectiveness is still not adequate. Effects based on the use of oxygen therapy and sorbents that potentiate the repair of tissue defects have proven appropriate in various areas of medicine. (7-9) $^{-1}$

The aim of our research was to study the effectiveness of the potentiation of reparative processes in soft tissues using $\mathrm{S}-\mathrm{HPOI}$ in the experiment. 


\section{Materials and Methods}

The study was performed at the Department of General Surgery, Voronezh State Medical University named after N. N. Burdenko. A special device was designed to implement the S-HPOI technique. This device consisted of a spray nozzle, a sorbent container, and a mixing chamber (Fig.1). S-HPOI in the wound therapy was applied from the distance of $10-15 \mathrm{~cm}$, at an angle of $30-45^{\circ}$ daily for 7 days (until the defect was closed). The study included 150 Wistar rats that were divided into 5 groups: four control groups and one experimental group. Each group included 30 animals.

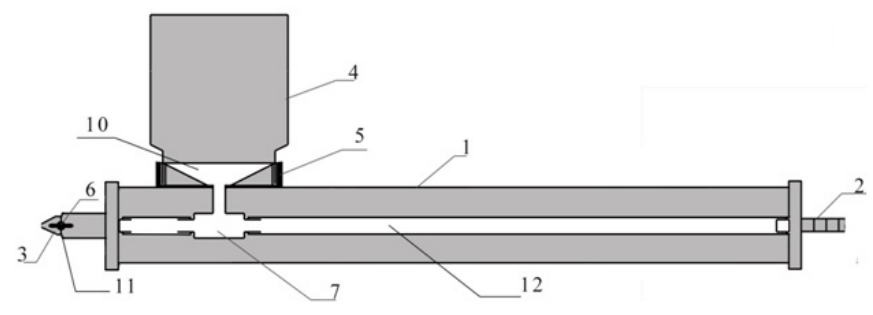

Fig. 1. Scheme of the device for the S-HPOI technique.

1-body, 2-connecting pipe, 3-spray nozzle, 4-container for a medication, 5 - connecting cover, 6 - fixing screw, 7 - mixing chamber, 10 - inner part of the connecting cover, 11 - pivot link, 12 - system of silicone tubes.

The identical soft tissue wounds were simulated in animals of all groups. No additional interventions were carried out in the animals of the control group (CG) 1; highpressure oxygen and air insufflation of wounds were applied in animals of CG2 and CG3, respectively; sorbent applications were performed for wound treatment in animals of CG4. The technique of S-HPOI was applied in animals of the experimental group (EG).

All animals included in the study were anesthetized by Zoletil-100. The wounds were simulated under aseptic conditions by excision in the area of the withers on the pattern of soft tissues with superficial fascia. The surgical field had been previously carefully shaved and treated with antiseptic solutions. The defect was washed with a $0.9 \%$ sodium chloride solution and covered with a sterile dressing.

The results of the experiment were assessed immediately after the simulation procedure, and on Days 1, 3, 5, 7, and 14 after wound simulation. The assessment included the animals' condition, the dynamics of symptoms of inflammation (soreness, swelling, hyperemia, hyperthermia, and exudation), the intensity of regeneration processes (the presence of granulations, epithelization, etc.), metrics (size and dynamics of the area of the defect), and morphological and statistical research methods.

Work on the animals was done in compliance with the principles of the Helsinki Declaration on the humane treatment of animals, stated in normative documents of the European community(86/609/EU), Manual on Experimental (Preclinical) Study of New Pharmacological Substances, and "Good laboratory practice" (MHRF Order No. 708H of 23.08.2010).
Statistical analysis was performed using the Statistica 6.1 software package (Stat-Soft Inc., USA). The normality of distribution of continuous variables was tested by the Kolmogorov-Smirnov test with the Lilliefors correction and Shapiro-Wilk test. For descriptive analysis, results are presented as mean \pm standard deviation (SD). For data with normal distribution, inter-group comparisons were performed using Student's t-test. Mann-Whitney U test and Wilcoxon criterion were used to compare means of variables not normally distributed. A probability value of $P<0.05$ was considered statistically significant.

\section{Results and Discussion}

Edema of paravual tissues was the most pronounced in animals of CG1 and it was improved on average in $3.26 \pm 0.27$ days; edema of paravual tissues was the least pronounced in animals of EG, and its elimination was registered in $2.47 \pm 0.32$ days after the defect was performed. In animals of CG2, CG3, and CG4, the studied parameter constituted $2.86 \pm 0.41$, $2.76 \pm 0.35$, and $2.72 \pm 0.27$ days, respectively (Table 1 ).

\section{Table 1.}

The relief of local signs of inflammation in the groups included in the study

\begin{tabular}{|l|c|c|c|}
\hline \multirow{2}{*}{ Group } & \multicolumn{3}{|c|}{ Time, days } \\
\cline { 2 - 4 } & Edema & Hyperemia & Wound discharge $^{1}$ \\
\hline CG1 & $3.26 \pm 0.27$ & $2.78 \pm 0.46$ & $3.55 \pm 0.36$ \\
\hline CG2 & $2.86 \pm 0.41$ & $2.67 \pm 0.54$ & $2.75 \pm 0.36$ \\
\hline CG3 & $2.76 \pm 0.35$ & $2.63 \pm 0.39$ & $2.75 \pm 0.36^{*}$ \\
\hline CG4 & $2.72 \pm 0.27 *$ & $2.51 \pm 0.35$ & $2.67 \pm 0.30^{*}$ \\
\hline EG & $2.47 \pm 0.32 *$ & $2.27 \pm 0.30$ & $2.42 \pm 0.38^{*}$ \\
\hline
\end{tabular}

Note: ${ }^{1}$ - towards minuscule discharge; $* P<0.05$ in comparison with CG1

Hyperemia in the wound area was retained mostly in animals of CG1 - up to $2.78 \pm 0.46$ days. Hyperemia in the wound area was cured most rapidly in animals of EG - up to $2.27 \pm 0.30$ days. The use of high-pressure oxygen and air insufflations of wounds arrested hyperemia in $2.67 \pm 0.54$ and $2.63 \pm 0.39$ days, respectively, and sorbent applications in $2.51 \pm 0.35$ days.

After wound simulation without treatment (CG1), the wound discharge disappeared, on average, in $3.55 \pm 0.36$ days; after use of oxygen and air insufflations - in $2.75 \pm 0.36$ days; after use of sorbent applications - in $2.67 \pm 030$ days.

There were no significant differences between groups in the wound area after simulation, and the wound area averaged $134.3 \pm 13.3 \mathrm{~mm}^{2}$ (Table 2).

In animals of CG1, the studied parameter steadily decreased during the entire observation period, compared to the initial size, by $37.6 \%, 60.8 \%, 77.6 \%$, and $86.9 \%$ on Days $1,3,7$, and 10 after wound simulation, respectively. In CG2 and CG3, the wound area was eliminated by $39.5 \%$ and $40.8 \%$ 
on Day $1,66.3 \%$ and $68,2 \%$ on Day $3,83.5 \%$ and $84.6 \%$ on Day 7 , and $92.9 \%$ and $93.6 \%$ on Day 10 , respectively, compared with the findings obtained before treatment. Sorbent applications in animals of CG4 resulted in a reduction in size of the defect by $39.0 \%, 71.6 \%, 88.4 \%$, and $98.2 \%$ on Days 1 , 3,7 , and 10 , respectively. S-HPOI in EG animals resulted in the reduction of the wound area by $42.7 \%, 74.0 \%, 90.3 \%$ and $99.5 \%$ on Days 1, 3, 7, and 10, respectively, compared with the sizes obtained immediately after wound simulation.

Table 2.

Dynamics of changes in the wound area, $\mathrm{mm}^{2}$

\begin{tabular}{|l|c|c|c|c|c|}
\hline \multirow{2}{*}{ Group } & \multicolumn{5}{|c|}{ Day after wound simulation } \\
\cline { 2 - 6 } & $\begin{array}{c}\text { Day of } \\
\text { simulation }\end{array}$ & Day 1 & Day 3 & Day 7 & Day 10 \\
\hline CG1 & $132.9 \pm 13.7$ & $87.1 \pm 8.58^{*}$ & $50.5 \pm 5.9^{*}$ & $22.4 \pm 3.2^{*}$ & $11.3 \pm 1.4^{*}$ \\
\hline CG2 & $133.3 \pm 12.9$ & $84.6 \pm 8.7^{*}$ & $43.6 \pm 6.2^{*}$ & $16.5 \pm 3.8^{*}$ & $6.1 \pm 1.4^{*, \wedge}$ \\
\hline CG3 & $135.4 \pm 12.1$ & $84.2 \pm 8.5^{*}$ & $41.8 \pm 5.4^{*}$ & $15.7 \pm 3.4^{*, \wedge}$ & $5.6 \pm 1.0^{*, \wedge}$ \\
\hline CG4 & $134.1 \pm 13.1$ & $85.9 \pm 8.4^{*}$ & $37.0 \pm 4.9^{*, \wedge}$ & $11.7 \pm 3.3^{*, \wedge}$ & $1.6 \pm 0.7^{*, \wedge}$ \\
\hline EG & $135.6 \pm 14.5$ & $81.6 \pm 8.1^{*}$ & $34.2 \pm 3.6^{*, \wedge}$ & $9.9 \pm 2.5^{*, \wedge 2}$ & $0.5 \pm 0.7^{*, \wedge}$ \\
\hline
\end{tabular}

Note: $*_{-} P<0.05$ in comparison with Day of simulation; $\wedge^{\wedge}-P<0.05$ in comparison with CG1

When studying the RNA level, we detected chromatophilic substances having different intensities most pronounced in the growth layers of the skin in animals of CG1 on Day 1 of the study; that fact indicated higher activity of metabolic processes in this area (Table 3). On Day 3, the severity of chromatophilic substances became more intense in the deep layers of the epidermis; in some cases, the basophilic material was located perinuclear. The OD (in relative units [RU]) of RNA in the epithelium on Days 1 and 3 was equal to $0.24 \pm 0.01 \mathrm{RU}$ and $0.26 \pm 0.01 \mathrm{RU}$; on Days 7 and 10, we found a further growth of the studied indicator to $0.30 \pm 0.01 \mathrm{RU}$ and $0.31 \pm 0.01 \mathrm{RU}$. The maximum number of SH-groups in animals of CG1 was determined in the deeper layers of the paravual epidermis. The OD of SH-groups in the growth layers was $0.26 \pm 0.01 \mathrm{RU}, 0.26 \pm 0.01 \mathrm{RU}, 0.28 \pm 0.02 \mathrm{RU}$, and $0.27 \pm 0.01 \mathrm{RU}$ on Days $1,3,7$, and 10 , respectively.

In CG2, on Day 1 after the procedure, HPOI resulted in moderate basophilia with a more pronounced reaction within the growth layer; and the OD parameters for RNA and SH-groups were equal to $0.25 \pm 0.01 \mathrm{RU}$ and $0.26 \pm 0.02 \mathrm{RU}$, respectively. On Day 3 after the procedure, metabolic activity was activated together with re-epithelialization of the wound area and was accompanied by stabilization of the studied parameters at the level equal to $0.27 \pm 0.01 \mathrm{RU}$ and $0.26 \pm 0.01 \mathrm{RU}$. On Day 7, the epidermis recovery resulted in an increase in the OD of RNA up to $0.31 \pm 0.02 \mathrm{RU}$. SHgroups in the indicated period were determined in the upper layers and amounted to $0.29 \pm 0.01 \mathrm{RU}$, which could indicate the activation of keratinization of the epithelium. On Day 10, the OD of RNA and SH-groups constituted $0.32 \pm 0.02 \mathrm{RU}$ and $0.27 \pm 0.01 \mathrm{RU}$, respectively.
Table 3.

Dynamics of optical density of RNA and SH-groups, $R U$

\begin{tabular}{|l|c|c|c|c|}
\hline \multirow{2}{*}{ Group } & \multicolumn{5}{|c|}{ Day after wound simulation } \\
\cline { 2 - 5 } & 1 & 3 & 7 & 10 \\
\hline \multicolumn{5}{|c|}{ Optical density of RNA } \\
\hline CG1 & $0.24 \pm 0.01$ & $0.26 \pm 0.01^{*}$ & $0.30 \pm 0.01^{*}$ & $0.31 \pm 0.02^{*}$ \\
\hline CG2 & $0.25 \pm 0.01$ & $0.27 \pm 0.01^{*}$ & $0.31 \pm 0.02^{*}$ & $0.32 \pm 0.02$ \\
\hline CG4 & $0.25 \pm 0.01$ & $0.27 \pm 0.01^{*}$ & $0.32 \pm 0.01^{* \wedge}$ & $0.32 \pm 0.01 *, \wedge$ \\
\hline EG & $0.26 \pm 0.01$ & $0.28 \pm 0.01^{*}$ & $0.32 \pm 0.02^{* \wedge}$ & $0.33 \pm 0.02$ \\
\hline & $0.26 \pm 0.01$ & $0.27 \pm 0.01$ & $0.32 \pm 0.02$ & $0.34 \pm 0.02$ \\
\hline CG1 & $0.26 \pm 0.01$ & $0.26 \pm 0.01$ & $0.28 \pm 0.02$ & $0.27 \pm 0.01$ \\
\hline CG2 & $0.26 \pm 0.02$ & $0.26 \pm 0.01$ & $0.29 \pm 0.01$ & $0.27 \pm 0.01$ \\
\hline CG3 & $0.27 \pm 0.02$ & $0.27 \pm 0.02$ & $0.29 \pm 0.01$ & $0.28 \pm 0.02$ \\
\hline CG4 & $0.28 \pm 0.02$ & $0.28 \pm 0.02$ & $0.31 \pm 0.02$ & $0.29 \pm 0.02$ \\
\hline EG & $0.28 \pm 0.02$ & $0.28 \pm 0.02$ & $0.34 \pm 0.02$ & $0.29 \pm 0.02$ \\
\hline $\begin{array}{l}\text { Note: } *-P<0.05 \text { in comparison with Day } 1 ;^{\wedge}-P<0.05 \text { in comparison } \\
\text { with CG1 }\end{array}$
\end{tabular}

In CG3, on Day 1 after intervention, the OD of RNA and SH-groups was $0.25 \pm 0.01 \mathrm{RU}$ and $0.27 \pm 0.02 \mathrm{RU}$, respectively. On Day 3, the OD of RNA increased to $0.27 \pm 0.01 \mathrm{RU}$, and the SH-group level was stabilized at $0.27 \pm 0.02 \mathrm{RU}$ together with the increased metabolic activity. On Days 7 and 10, the restoration of damaged RNA was observed with an increase in the OD of RNA up to $0.32 \pm 0.01 \mathrm{RU}$ and $0.32 \pm 0.01 \mathrm{RU}$, SHgroups - up to $0.29 \pm 0.01 \mathrm{RU}$ and $0.28 \pm 0.02 \mathrm{RU}$, respectively.

In CG4, on Day 1 after sorbent applications, the OD of RNA and SH-groups was $0.26 \pm 0.01 \mathrm{RU}$ and $0.28 \pm 0.02 \mathrm{RU}$, respectively. The growth in the SH-group level in this case demonstrates increased metabolism and increased soft tissue regeneration. On Day 3, the OD of RNA was equal to $0.28 \pm 0.01 \mathrm{RU}$; at the same time, the OD of SH-groups remained at the initial level. On Days 7 and 10, the wound was filled with the formed epidermis and the OD of RNA reached $0.32 \pm 0.02 \mathrm{RU}$ and $0.33 \pm 0.02 \mathrm{RU}$, and the SH-group level $0.31 \pm 0.02 \mathrm{RU}$ and $0.29 \pm 0.02 \mathrm{RU}$, respectively.

Similar dynamics of the changes in metabolic processes was registered in animals of EG after S-HPOI: the growth of RNA and SH-groups as the defect was further epidermized and the epidermis differentiated; these processes subsequently decreased as stratification processes completed. On the indicated days, the RNA level constituted $0.26 \pm 0.01 \mathrm{RU}$, $0.27 \pm 0.01 \mathrm{RU}, 0.32 \pm 0.02 \mathrm{RU}$ and $0.34 \pm 0.02 \mathrm{RU}$, and for SHgroups: $0.28 \pm 0.02 \mathrm{RU}, 0.28 \pm 0.02 \mathrm{RU}, 0.34 \pm 0.02 \mathrm{RU}$, and $0.28 \pm 0.02 \mathrm{RU}$.

In conclusion, we can state the following:

- The use of high-pressure oxygen has practically no benefits in wound treatment compared to similar intervention using air jet.

- The use of the sorbent applications and S-HPOI contributed to a significant acceleration of reparative processes 
by 1.1-1.3 and 1.2-1.5 times, respectively, compared with the results obtained in animals of CG1. On the whole, S-HPOI resulted in the maximum reduction in the area of soft tissue wounds: by $74.0 \%$ in 3 days, by $99.5 \%$ in 10 days compared to the initial findings.

- A higher reparative activity when using the sorbent is supported by parameters of the level of RNA and SH-groups, compared to findings obtained in the animals of other groups where sorbent was not applied.

\section{Competing Interests}

The authors declare that they have no competing interests.

\section{Sources of Funding}

The work was supported by the Russian Federation President Council on Grants for governmental support for young Russian scientists and leading RF scientific schools (Grant HШ-2552.2020.7).

\section{References}

1. Kuzin MI, Kostyuchenok BM. Wounds and wound infection. Moscow: Meditsina; 1990. [In Russian].

2. Akers KS, Mende K, Cheatle KA, Zera WC, Yu X, Beckius ML, et al.; Infectious Disease Clinical Research Program Trauma Infectious Disease Outcomes Study Group.
Biofilms and persistent wound infections in United States military trauma patients: a case-control analysis. BMC Infect Dis. 2014;14:190. Published 2014 Apr 8. doi:10.1186/14712334-14-190

3. Murphy-Lavoie HM, Bhimji SS. Diabetic, Foot infections. Treasure Island (FL): StatPearls Publishing; 2017.

4. Izmailov AG, Dobrokvashin SV, Volkov DE, Pyrkov VA, Zakirov RF, Davlet-Kildeev SA. [New approaches in local drug treatment of infected wounds in soft tissue]. Practical medicine. 2015;91(6):67-72. [Article in Russian].

5. Gluhov AA, Andreev AA, Shmarin AA, Lobas SV. [Barbotage sanitation in surgical treatment of diabetic foot syndrome]. Infektsii v Hirurgii. 2018;16(1-2): 83-84. [Article in Russian].

6. Smotrin SM, Oslavskii AI, Melamed VD, Grakovich PN. Sorption-drainage devices in complex treatment of purulent wounds and soft tissue abscesses. Novosti Khirurgii. 2016;24(5):457-464. [Article in Russian].

7. Shulutko AM, Osmanov EG, Gogokhiya TR, Khmyrova SE. [Application of plasma flows in patients with surgical soft tissue infection]. Vestn Khir Im I I Grek. 2017;176(1):65-69. [Article in Russian].

8. Vinnik YS, Plakhotnikova AM, Kirichenko AK. [The use of a directed flow of ozone-oxygen gas mixture to sanitize a purulent wound in the experiment]. Novosti Khirurgii. 2015;23(4): 372-378. [Article in Russian].

9. Girev EA, Zarivchatskii MF, Orlov OA, Shavkunov SP. [Investigation of the concentration of oxygen in soft tissues of an operative wound edge in stomach cancer surgery]. Family Health - the 21 Century. 2015;1(1):57-67. [Article in Russian]. 